\title{
Interfaces between bariatric surgery and oral health. A longitudinal survey ${ }^{1}$
}

\author{
Interface entre cirurgia bariátrica e saúde bucal. Estudo longitudinal
}

\author{
Juliane Avansini Marsicano ${ }^{\mathrm{I}}$, Patrícia Garcia de Moura Grec ${ }^{\mathrm{II}}$, Lídia Barbieri Belarmino ${ }^{\mathrm{III}}$, Reginaldo Ceneviva ${ }^{\mathrm{IV}}$, Sílvia Helena \\ de Carvalho Sales Peres ${ }^{\mathrm{V}}$
}

IFellow PhD degree, Division Public Health, Department of Pediatric Dentistry, Orthodontics and Public Health, Bauru School of Dentistry, University of Sao Paulo (USP), Brazil. Responsible for designing the protocol, involved in collection and processing of study information, manuscript writing. ${ }^{\text {IF} F e l l o w ~ P h D ~ d e g r e e, ~ D i v i s i o n ~ P u b l i c ~ H e a l t h, ~ D e p a r t m e n t ~ o f ~ P e d i a t r i c ~ D e n t i s t r y, ~ O r t h o d o n t i c s ~ a n d ~ P u b l i c ~ H e a l t h, ~ B a u r u ~ S c h o o l ~ o f ~ D e n t i s t r y, ~ U S P, ~}$ Sao Paulo, Brazil. Helped with collection and processing of study information.

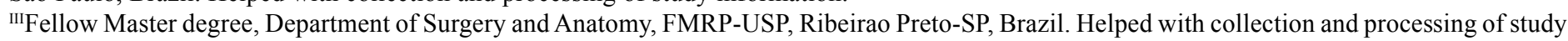
information.

${ }^{\text {IV }}$ Chairman, Full Professor and Volunteer Faculty, Division of Digestive Surgery, Department of Surgery and Anatomy, FMRP-USP, Ribeirao Preto-SP, Brazil. Helped to design the protocol, responsible for intellectual and scientific content of the study, critical revision, performed the surgical interventions.

${ }^{v}$ Associate Professor, Division Public Health, Department of Pediatric Dentistry, Orthodontics and Public Health, Bauru School of Dentistry, USP, Sao Paulo, Brazil. Helped to design the protocol and supervised all phases of the study, responsible for intellectual and scientific content of the study, critical revision.

\begin{abstract}
PURPOSE: To evaluate oral changes, such as dental caries, periodontal disease, dental wear and salivary flow in bariatric patients. Fifty four obese patients who underwent bariatric surgery were studied before ( $n=54)$, up after 3 months ( $n=24)$ and 6 months $(n=16)$. METHODS: Indices for evaluating oral conditions were: DMFT, CPI, DWI and salivary flow. OIDP questionnaire was used to assess the impact of oral health on quality of life. ANOVA and Spearman correlation were used $(\mathrm{p}<0.05)$.

RESULTS: DMFT was $17.6 \pm 5.7,18.4 \pm 4.1$ and $18.3 \pm 5.5(\mathrm{P}>0.05)$, presence of periodontal pockets in $50 \%, 58 \%$ and $50 \%$ of patients ( $\mathrm{p}>0.05$ ), tooth wear in dentin present in $81.5 \%, 87.5 \%$ and $87.5 \%$ before, 3 and 6 months after surgical treatment respectively. There were differences between the three periods for prevalence and severity of dental wear $(\mathrm{p}=0.012)$. Salivary flow was $0.8 \pm 0.5 \mathrm{ml} / \mathrm{min}$ before surgery, $0.9 \pm 0.5 \mathrm{ml} / \mathrm{min}$ for 3 months and $1.1 \pm 0.5 \mathrm{~m} / \mathrm{min}$ for 6 months $(\mathrm{p}>0.05)$. The impact of oral health on quality of life decreased with time after bariatric surgery $(\mathrm{p}=0.029)$.

CONCLUSION: The lifestyle changes after bariatric surgery and these changes may increase the severity of pre-existing dental problems. However, these alterations in oral health did not influence the quality of life.

Key words: Oral Health. Tooth Erosion. Dental Caries. Xerostomia. Obesity. Bariatric Surgery.
\end{abstract}

\section{RESUMO}

OBJETIVO: Avaliar alterações bucais, como cárie dentária, doença periodontal, desgaste dentário e fluxo salivar, em pacientes bariátricos.

MÉTODOS: Cinquenta e quatro pacientes obesos, submetidos à cirurgia bariátrica, tiveram suas condições bucais avaliadas antes $(n=54)$, aos 3 meses $(n=24)$ e aos 6 meses $(n=16)$ após a cirurgia bariátrica. Os índices para avaliação das condições bucais foram: CPOD, IPC, IDD e o volume de fluxo salivar. O questionário OIDP foi utilizado para verificar o impacto da saúde bucal na qualidade de vida. ANOVA e correlação de Spearman foram utilizados para análise estatística $(\mathrm{p}<0,05)$.

RESULTADOS: CPOD foi 17,6 $\pm 5,7,18,4 \pm 4,1$ e 18,3 $\pm 5,5(\mathrm{p}>0,05)$, bolsa periodontal foi encontrada em $50 \%$, 58\% e 50\% dos pacientes $(\mathrm{p}>0,05)$ e o desgaste dentário em dentina em $81,5 \%, 87,5 \%$ e 87,5\% dos pacientes, respectivamente antes, 3 meses e 6 meses após a cirurgia bariátrica. Houve diferença significativa entre os três períodos estudados, quanto à prevalência e à severidade do desgaste dentário $(\mathrm{p}=0,012)$. O fluxo salivar foi $0,8 \pm 0,5 \mathrm{ml} / \mathrm{min}$ antes, $0,9 \pm 0,5 \mathrm{ml} / \mathrm{min}$ aos 3 e 1,1 $\pm 0,5 \mathrm{ml} / \mathrm{min}$ aos $6 \mathrm{meses}$ após cirurgia $(\mathrm{p}>0,05)$. O impacto da saúde bucal na qualidade de vida diminuiu com o tempo decorrido após cirurgia bariátrica $(\mathrm{p}=0,029)$.

CONCLUSÕES: As mudanças no estilo de vida após a cirurgia bariátrica podem aumentar a gravidade de problemas bucais pré-existentes. Entretanto, esta alteração na condição bucal pode não influenciar a qualidade de vida.

Descritores: Saúde Bucal. Erosão Dentária. Cárie Dentária. Xerostomia. Obesidade. Cirurgia Bariátrica. 


\section{Introduction}

Obesity is a chronic disease that has reached pandemic proportions to the extent that it is recognized as one of the major public health challenges facing both developed and third world countries $^{1}$ and is related to important socioeconomic problems. It is estimated that more than half of the European population are overweight (body mass index- BMI $>25 \mathrm{~kg} / \mathrm{m} 2$ ) and up to $30 \%$ are obese (BMI $>30 \mathrm{~kg} / \mathrm{m} 2$ ). In the USA, $64 \%$ of the population are estimated to be overweight or obese. The prevalence of obesity has increased significantly in Brazil ${ }^{2}$ and is estimated that 38.8 million (40.6\%) adults are overweight.

Morbid obesity is associated with many health problems, such as development of diabetes mellitus, arterial hypertension, an increased incidence of certain forms of cancer, respiratory complications (sleep obstructive apnea), among other co-morbidities ${ }^{1,3}$ Obesity is also related to several aspects of oral health such as caries, periodontitis and xerostomia ${ }^{1,4}$.

Gastrointestinal surgical interventions represent a treatment for morbid obesity with a lasting effect on weight control ${ }^{5}$ because this treatment has provided the most efficacious and durable weight loss solutions for obese individuals. In addition, it reduces the risks of severe co-morbidities in obesity class III and obesity class $\mathrm{II}^{1,2,5-7}$. The rate of bariatric surgical procedures has increased significantly, and this has been attributed to current epidemic obesity ${ }^{8}$.

However, some bariatric surgeries can produce adverse effects such as gastroesophageal reflux, nausea, vomiting, malnutrition, anemia, dehydration, vitamin and mineral deficiencies (calcium, iron, folic acid, vitamin $\mathrm{B}_{12}$ and D) among others ${ }^{7,9-11}$. This occurs because in most cases there are dysfunctional eating habits, such as overeating, eating too fast, or not chewing food well ${ }^{7-9}$. The side-effects of bariatric surgery may be reflected in the oral cavity and can cause alterations in oral health ${ }^{7,8,10-12}$, such as dental caries, periodontal diseases, xerostomia and dentin hypersensitivity ${ }^{8,10,12-14}$.

There are few studies in the scientific literature evaluating the interfaces of dental aspects and side-effects of bariatric surgery. The aim of the present study was to verify oral alterations in patients before and after bariatric surgery, identify the occurrence of dental caries, periodontal diseases and dental wear, and to correlate oral health with quality of life in these patients.

\section{Methods}

This survey was approved by the Research Ethics Committee of the Clinical Hospital of the Faculty of Medicine of Ribeirão Preto, University of São Paulo, Brazil, (Process 12386/2009).

The present investigation was designed as a longitudinal analysis of the interfaces of bariatric surgery and oral health in patients before, 3 and 6 months after bariatric surgery.

The sample consisted of 54 obese patients with a mean age of $40.5 \pm 9.7$ year, being 44 females and 10 males who underwent Roux - en - Y Gastric Bypass (RYGB) at Clinical Hospital of the Faculty of Medicine, Ribeirão Preto, University São Paulo and were followed up after 3 months $(n=24)$ and 6 months $(n=16)$.
Clinical examinations were performed to observe the average number of decayed, missing or filled teeth (DMFT Index), and the periodontal condition was evaluated by bleeding, calculus, pocket depth of $3.5-5.5 \mathrm{~mm}$, or pocket depth $>6 \mathrm{~mm}$ (CPI index), all procedures in accordance to the World Health Organization (WHO) criteria.

To evaluate dental wear the DWI (Dental Wear Index) described by Sales-Peres et al. ${ }^{15}$ was used. The criteria for examination were: (0- normal: no evidence of wear; 1 - incipient: tooth wear in enamel; 2- moderate: tooth wear in dentin; 3- severe: tooth wear in pulp or secondary dentin; and 4- restored: tooth wear leading to restoration; 5- non-assessed).

The clinical examinations were performed by a previously calibrated dental examiner (Kappa values ranged between 0.91 and 0.84).

Saliva stimulated by chewing paraffin wax for 5 minutes was spat into a small cup, and measured with syringe. The saliva flow was classified as normal $(>1.0 \mathrm{ml} / \mathrm{min})$ and hyposalivation $(<1.0 \mathrm{ml} / \mathrm{min})^{16}$.

The OIDP instrument includes physical, psychological and social aspects of daily performance ${ }^{17}$. The index is composed of 8 questions that comprise: (a) functional performance: 1) eating and enjoying food 2) cleaning teeth 3) speaking and pronouncing words; (b) psychological performance: 4) smiling 5) emotional stability 6) sleeping and relaxing; (c) social performance: 7) working 8) contact with people ${ }^{17}$. The occurrence was recorded in a dichotomous manner (yes/no). Patients who answered 'yes' to any item were asked about the frequency and severity using a five-point scale. For the frequency, the scale alternatives varied from a long time (regularly) to short time (rarely). For the severity, the scale varied from one to five points. The impact scores on each performance were calculated by multiplying frequency and severity scores. The sum of the eight scores was divided by the maximum possible score (200) $)^{17}$. In this study the OIDP score was dichotomized into having at least one daily performance affected versus no daily performance affected.

The patients were asked about the frequency of vomiting.

The data were analyzed using the test ANOVA repeated measures to verify difference of obtained values before bariatric surgery and 3 and 6 months after surgery. Spearman correlation was used to verify association between the saliva flow and oral diseases. A personal computer with the Statistica 7.0. program was used. The level of significance was $\mathrm{p} \leq 0.05$.

\section{Results}

The mean DMFT index (dental caries) was $17.6 \pm 5.7$ for obese patients, $18.4 \pm 4.1$ for 3 months and $18.3 \pm 5.5$ for 6 months after surgery $(\mathrm{p}>0.05)$ (Table1).

TABLE 1 - Mean and standard deviation of the DMFT index conditions

\begin{tabular}{cccccc}
\hline Period & Healthy & Decayed & Filled & Missing & DMFT \\
\hline Obese & $11.5 \pm 6.1^{\mathrm{A}}$ & $1.4 \pm .8^{\mathrm{A}}$ & $9.1 \pm 5.8^{\mathrm{A}}$ & $6.7 \pm 7.1^{\mathrm{A}}$ & $17.6 \pm 5.7^{\mathrm{A}}$ \\
$3 \mathrm{M}$ & $10.0 \pm 5.0^{\mathrm{A}}$ & $0.1 \pm 0.3^{\mathrm{B}}$ & $10.4 \pm 5.8^{\mathrm{A}}$ & $6.9 \pm 6.3^{\mathrm{A}}$ & $18.4 \pm 4.1^{\mathrm{A}}$ \\
$6 \mathrm{M}$ & $11.6 \pm 5.3^{\mathrm{A}}$ & $0.3 \pm 0.6^{\mathrm{AB}}$ & $11.5 \pm 7.3^{\mathrm{A}}$ & $6.3 \pm 6.9^{\mathrm{A}}$ & $18.3 \pm 5.5^{\mathrm{A}}$
\end{tabular}


Different upper case letters in the same column indicate statistical significance among the experimental conditions $(\mathrm{p}<0.05)$.

Significant difference was found for only decayed teeth $(p=0.004) ; 25 \%$ of patients presented at least one decayed tooth 6 months after bariatric surgery.

Periodontal diseases were shown to be present in $90.8 \%$ of the sextants before in $100 \%$ of the sextants in 3 months and 6 months after surgery. The severity of periodontal diseases increased by $16.7 \%$ and $12.5 \%$ after 3 and 6 months respectively. The prevalence of periodontal pockets, in at least one tooth evaluated was $50.0 \%$ before and 6 months and 58.4\% in 3 months (Table 2).

TABLE 2 - Distribution of patients according to CPI index conditions

\begin{tabular}{ccccc}
\hline \multirow{2}{*}{ Period } & Healthy & Bleeding & Calculus & Pocket depth \\
\cline { 2 - 5 } & $\mathrm{n}(\%)$ & $\mathrm{n}(\%)$ & $\mathrm{n}(\%)$ & $\mathrm{n}(\%)$ \\
\hline Obese & $5(9.2 \%)$ & $1(1.8 \%)$ & $21(39.0 \%)$ & $27(50.0 \%)$ \\
$3 \mathrm{M}$ & $0(0 \%)$ & $0(0 \%)$ & $10(41.6 \%)$ & $14(58.4 \%)$ \\
$6 \mathrm{M}$ & $0(0 \%)$ & $0(0 \%)$ & $8(50.0 \%)$ & $8(50.0 \%)$ \\
\hline
\end{tabular}

All patients had some degree of dental wear, the mean DWI was $25.4 \pm 9.3$ in before surgery, $27.4 \pm 12.7$ in 3 months and $32.7 \pm 10.2$ in 6 months after; significant differences were found between before, 3 and 6 months after bariatric surgery $(p=0.012)$ (Table 3).

TABLE 3 - Distribution of patients according to DWI index conditions

\begin{tabular}{ccccc}
\hline \multirow{2}{*}{ Period } & Healthy & Enamel & Dentin & DWI \\
\cline { 2 - 5 } & $\mathrm{n}(\%)$ & $\mathrm{n}(\%)$ & $\mathrm{n}(\%)$ & $\operatorname{mean} \pm \mathrm{SD}$ \\
\hline Obese & $0(0 \%)$ & $8(14.8 \%)$ & $46(85.2 \%)$ & $25.4 \pm 9.3^{\mathrm{A}}$ \\
$3 \mathrm{M}$ & $0(0 \%)$ & $3(12.5 \%)$ & $21(87.5 \%)$ & $27.4 \pm 12.7^{\mathrm{AB}}$ \\
$6 \mathrm{M}$ & $0(0 \%)$ & $0(0 \%)$ & $14(100 \%)$ & $32.7 \pm 10.2^{\mathrm{B}}$ \\
\hline
\end{tabular}

Different upper case letters in the same column indicate statistical significance among the experimental conditions $(\mathrm{p}<0.05)$.

Salivary flow was $0.8 \pm 0.5 \mathrm{ml} / \mathrm{min}$ before, $0.9 \pm 0.5$ $\mathrm{ml} / \mathrm{min}$ for 3 months $1.1 \pm 0.5 \mathrm{ml} / \mathrm{min}$ for 6 months after surgery $(p>0.05)$. There was no correlation between saliva flow and DMFT, periodontal diseases and dental wear $(\mathrm{p}>0.05)$.

The impact of oral health on quality of life decreased with time after bariatric surgery $(p=0.029)$ (Table 4).
TABLE 4 - Mean and standard deviation of the OIDP index

\begin{tabular}{lc}
\hline & OIDP \\
\hline Pré & $26.0 \pm 43.8^{\mathrm{A}}$ \\
Pós 3 meses & $15.5 \pm 29.0^{\mathrm{AB}}$ \\
Pós 6 meses & $2.5 \pm 5.4^{\mathrm{B}}$ \\
\hline $\begin{array}{l}\text { Different upper case letters in the same } \\
\text { column indicate statistical significance } \\
\text { among the experimental conditions } \\
(\mathrm{p}<0.05)\end{array}$
\end{tabular}

As regard frequency of vomiting, 24.6 percent before, 47.8 percent 3 months and 56.3 percent 6 months after surgery reported vomiting at least once a week.

\section{Discussion}

This study evaluated the oral health conditions of severe obesity patients who underwent bariatric surgery, including oral health aspects and possible side-effects of bariatric surgery.

The strategy for management of the public health problem of obesity should be based mainly on preventive practice, concentrating on changes in lifestyle and behavior, and not addressed exclusively on the demands for services that obesity comorbities generate. Clinically significant obesity has become a global epidemic with great socioeconomic implications for health systems. The rate of bariatric surgical procedures has increased significantly because the surgery represents the most efficient treatment for morbid obesity with a lasting effect on weight control ${ }^{5,8}$. Bariatric surgery improves health, quality of life and long-term weight loss, and this is sufficient to reduce obesity-related comorbidities. In the morbidly obese population, surgery may reduce the relative risk of death by $89 \%$.

The surgical technique used in patients in this study was RYGB that corresponds to restrictive and disabsorptive bariatric surgery, in which the restrictive component has a major clinical significance. The technique involves reduction of gastric capacity and placement of a restrictive ring, resulting in a desirable decrease of food ingestion. Exclusion of the duodenum and segment of the jejunum, in addition to inadequate ingestion of foods, may favor calcium, iron, folic acid, vitamin B12, A, D, E and K deficiency ${ }^{7,9}$.

The oral condition of obese patients may change after bariatric surgery, because this procedure may have side-effects capable of causing alteration in the oral cavity ${ }^{10}$.

Standard dietary recommendations for bariatric patients include small frequent meals (4-6/day), through and slow chewing, and sipping fluids throughout the day. These frequent and prolonged meal times could be related to an increased risk of dental caries in these patients ${ }^{14}$. In this longitudinal survey 
the patient's history of dental caries was evaluated through the DMFT index. It was verified that the DMFT increased after surgery both after 3 months and 6 months, but this difference was not significant. However, after 6 months of bariatric surgery, $25 \%$ of the patients presented more decayed teeth when compared with their situation before surgery $(\mathrm{p}=0.004)$. Hague et al. ${ }^{8}$ followed-up a patient after bariatric surgery and concluded that the patient had an increase of dental caries. Although the exams performed to evaluate dental caries in this study (clinical examination) and in the cited study ${ }^{8}$ (supplementary examination and radiography) were different, in both studies an increase in dental caries was verified after bariatric surgery.

As regards the greater incidence of dental caries, Hague et al. ${ }^{8}$ suggested that the difference may be related to increased frequency of food ingestion by patients after bariatric surgery, capable of resulting in increased plaque indexes, gingivitis and serious periodontal diseases, as was found in their study. The present study found that the prevalence of periodontal diseases increased in the two periods of evaluation after bariatric surgery when compared with the time before surgery (only $9.2 \%$ of the sextants were healthy in obese patients in contrast with no sextants after bariatric surgery).

The prevalence of periodontal pockets before bariatric surgery was $50 \%$ before surgery patients, and increased to $58.4 \%$ 3 months after RYGB. This increase was also found by Pataro et al. (2011) in cross-sectional study that verified the prevalence of periodontitis ranging from $70.69 \%$ to $91.66 \%$ among groups before and after bariatric surgery. After bariatric surgery, bone loss frequently occurs because the patients may present metabolic bone disease (osteomalacia and osteoporosis) ${ }^{18,19}$. Bypassing the antrum and duodenum results in decreased absorption of several nutrients including iron, folate, calcium and vitamin B-12, which can cause bone $\operatorname{loss}^{7,9}$. As a result of this metabolic bone disease, some bariatric patients may present osteoporosis that could influence the bone loss in chronic periodontitis, and may be a co-factor in alveolar bone $\operatorname{loss}^{20}$.

All obese patients had some degree of dental wear, however the severity of dental wear increased with time after bariatric surgery. Statistically significant differences were found between before, 3 months and 6 months after bariatric surgery $(\mathrm{p}=0.012)$. This increased result may be related to chronic vomiting, because any acid below the critical $\mathrm{pH}$ of dental enamel (5.5) can dissolve hydroxyapatite crystals. Vomiting and other gastric disorders are important risk factors for tooth wear, and after bariatric surgery, nausea and vomiting may occur. In most cases dysfunctional eating habits, such as overeating, eating too fast, or not chewing food well may cause these complications ${ }^{7,9}$. In this longitudinal survey the patients showed increased vomiting frequencies of at least once a week after RYGB. Heling et al ${ }^{10}$ found that $37 \%$ of the patients who had undergone bariatric surgery had hypersensitive teeth. Hypersensitivity is a complication of dental erosion when there is dentin involvement.

Saliva has a broad range of protective functions for both oral tissues and the body at large, and contains a wide variety of effective antimicrobial substances against bacteria, viruses and fungi. Saliva also contains other chemoprotective factors that help to neutralize microbial damage and render environmental toxins less harmful ${ }^{21,22}$. Due to reduced gastric capacity dehydration is also a common concern. Inadequate water intake contributes to xerostomia, which can increase caries activity, periodontal disease and tooth wear ${ }^{8,9}$. In this study, saliva flow was reduced in patients before surgery and increased after RYGB, however, the patients continued to experience hyposalivation 3 months after surgery. After 6 months the saliva flow returned to normal. This reduction in salivary flow in patients before surgery and newly operated patients may be associated with the treatment for diabetes in most obese patients ${ }^{23}$. Whereas, the use of medications for hypertension, diabetes, hyperlipidemia and antidepressants decreased significantly after only 3 months of bariatric surgery ${ }^{23}$. The reduction in the use of medication may have influenced the improvement in salivary flow, such as hyposalivation, that was related to diabetic decompensation and the administration of certain drugs $^{24}, 6$ months after bariatric surgery.

The health benefits of gastric bypass are well established and include improvement in quality of life, which is an important component of the benefit realized by many postoperative bariatric surgery patients ${ }^{17}$. In this study it was verified that the impact of oral health on quality of life decreased with time after bariatric surgery, in spite of the increase in certain oral disorders, such as dental caries and dental wear. Although bariatric surgery may cause some systemic and oral changes, the benefits to the patient's health and quality of life produced by bariatric surgery, are much greater than its side-effects. However, it requires attendance by a multiprofessional staff to minimize the side-effects of surgery.

The maintenance of oral health is very important before and after bariatric surgery, considering that after surgery patients need to chew slowly and for a longer time to prevent adverse effects, such as nausea and vomiting. Therefore oral rehabilitation of patients undergoing bariatric surgery is essential in order to reduce the side-effects after surgery and improve the quality of life of patients before and after the intervention.

\section{Conclusions}

After bariatric surgery patients showed an increase in the occurrence of dental caries and in the severity of tooth wear, however these alterations in oral health status did not influence the quality of life, probably as a result of the significant improvement in the general health of these patients. On the other hand, the maintenance of oral health conditions may be considered a good strategy for preventing some of the side-effects of bariatric surgery.

\section{References}

1. Mathus-Vliegen EM, Nikkel D, Brand HS. Oral aspects of obesity. Int Dent J. 2007;57:249-56.

2. Barreto Villela N, Braghrolli Neto O, Lima Curvello K, Eduarda Paneili B, Seal C, Santos D, Cruz T. Quality of life of obese patients submitted to bariatric surgery. Nutr Hosp. 2004;19:367-71

3. Kopelman PG. Obesity as a medical problem. Nature. 2000;404:635-43.

4. Saito T, Shimazaki Y, Kiyohara Y, Kato I, Kubo M, Iida M, Yamashita

Y. Relationship between obesity, glucose tolerance, and periodontal disease in Japanese women: the Hisayama study. J Periodontal Res. 2005;40:346-53

5. Ovrebo KK, Hatlebakk JG, Viste A, Bassoe HH, Svanes K. Gastroesophageal reflux in morbidly obese patients treated with gastric banding or vertical banded gastroplasty. Ann Surg. 1998;228:51-8. 
6. Loss AB, de Souza AA, Pitombo CA, Milcent M, Madureira FA. Analysis of the dumping syndrome on morbid obese patients submitted to Roux en Y gastric bypass. Rev Col Bras Cir. 2009;36:413-9.

7. Arasaki CH, Del Grande JC, Yanagita ET, Alves AK, Oliveira DR. Incidence of regurgitation after the banded gastric bypass. Obes Surg. 2005; 15:1408-17.

8. Hague AL, Baechle M. Advanced caries in a patient with a history of bariatric surgery. J Dent Hyg. 2008;82:22-7.

9. Shikora SA, Kim JJ, Tarnoff ME. Nutrition and gastrointestinal complications of bariatric surgery. Nutr Clin Pract. 2007;22:29-40.

10. Heling I, Sgan-Cohen HD, Itzhaki M, Beglaibter N, Avrutis O, Gimmon Z. Dental complications following gastric restrictive bariatric surgery. Obes Surg. 2006;16:1131-4.

11. Suter M, Paroz A, Calmes JM, Giusti V. European experience with laparoscopic Roux-en-Y gastric bypass in 466 obese patients. Br J Surg. 2006;93:726-32.

12. Mandel L, Da Silva K. Parotid hypertrophy and bariatric surgery: case report. J Oral Maxillofac Surg. 2008;66:572-4.

13. Archer-Dubon C, Esquivel-Pedraza L, Ramirez-Anguiano J. Palatal ulcers due to vomiting after gastric band tightening. Obes Surg. 2007; 17:556-8.

14. Greenway SE, Greenway FL. Root surface caries: a complication of the jejunoileal bypass. Obes Surg. 2000;10:33-6.

15. Sales-Peres SHdC, Goya S, Araújo JJ, Sales-Peres A, Lauris JR, Magalhães MAR. Prevalence of dental wear among 12-year-old Brazilian adolescents using a modification of the tooth wear index. Public Health. 2008; $122: 942-8$.
16. Navarro MFL, Côrtes DF. Avaliação e tratamento do paciente com relação ao risco de cárie. Maxi-Odonto: dentística.1995;1:1-16.

17. Adulyanon S, Vourapukjaru J, Sheiham A. Oral impacts affecting daily performance in a low dental disease Thai population. Community Dent Oral Epidemiol. 1996;24:385-9.

18. Compher CW, Badellino KO, Boullata JI. Vitamin D and the bariatric surgical patient: a review. Obes Surg. 2008;18:220-4.

19. de Prisco C, Levine SN. Metabolic bone disease after gastric bypass surgery for obesity. Am J Med Sci. 2005;329:57-61.

20. Nicopoulou-Karayianni K, Tzoutzoukos P, Mitsea A, Karayiannis A, Tsiklakis K, Jacobs R,Lindh C, van der Stelt P, Allen P, Graham J, Horner K, Devlin H, Pavitt S, Yuan J. Tooth loss and osteoporosis: the OSTEODENT Study. J Clin Periodontol. 2009;36:190-7.

21. Gandara BK, Truelove EL. Diagnosis and management of dental erosion. J Contemp Dent Pract. 1999;1:16-23.

22. Turner MD, Ship JA. Dry mouth and its effects on the oral health of elderly people. J Am Dent Assoc. 2007;138:15S-20S.

23. Cercato C, Roizenblatt VA, Leança CC, Segal A, Lopes Filho AP, Mancini MC, Halpern A. A randomized double-blind placebocontrolled study of the long-term efficacy and safety of diethylpropion in the treatment of obese subjects. Int J Obes. 2009;33:857-65.

24. von Bültzingslöwen I, Sollecito TP, Fox PC, Daniels T, Jonsson R, Lockhart PB, Wray D,Brennan MT, Carrozzo M, Gandera B, Fujibayashi T, Navazesh M, Rhodus NL, Schiødt M. Salivary dysfunction associated with systemic diseases: systematic review and clinical management recommendations. Oral Surg Oral Med Oral Pathol Oral Radiol Endod. 2007;103:S57 e1-15.

\section{Correspondence:}

Juliane Avansini Marsicano

Departamento de Saúde Coletiva

Al. Otávio Pinheiro Brizola, 9-75

17012-901 Bauru-SP Brasil

Tel.:(55 14)3234-8863

\section{Conflict of interest: none}

Financial source: none

${ }^{1}$ Research performed at Department of Pediatric Dentistry, Orthodontics an Public Health, Bauru School of Dentistry, University of Sao Paulo (USP) and Department of Surgery, Faculty of Medicine of Ribeirao Preto, University of Sao Paulo (FMRP-USP), Ribeirao Preto-SP, Brazil.

Presented at the XII National Congress on Experimental Surgery of the Brazilian Society for Development of Research in Surgery-SOBRADPEC, 2011 October 26-29 Ribeirao Preto-SP, Brazil. 